\title{
Anion dependence of camel-shape capacitance at the interface between mercury and ionic liquids studied using pendant drop method
}

\section{$\operatorname{AUTHOR}(\mathrm{S}):$}

Nishi, Naoya; Yasui, Shunsuke; Hashimoto, Atsunori; Sakka, Tetsuo

\section{CITATION:}

Nishi, Naoya ... [et al]. Anion dependence of camel-shape capacitance at the interface between mercury and ionic liquids studied using pendant drop method. Journal of Electroanalytical Chemistry 2017, 789: 108-113

\section{ISSUE DATE:}

2017-03-15

\section{URL:}

http://hdl.handle.net/2433/254673

\section{RIGHT:}

(c) 2017. This manuscript version is made available under the CC-BY-NC-ND 4.0 license http://creativecommons.org/licenses/by-nc-nd/4.0/.; この論文は出版社版でありません 。引用の際には出版社版をご確認ご利用ください。; This is not the published version. Please cite only the published version. 


\title{
Anion dependence of camel-shape capacitance at the interface between mercury and ionic liquids studied using pendant drop method
}

\author{
Naoya Nishi*, Shunsuke Yasui, Atsunori Hashimoto, and Tetsuo Sakka \\ Department of Energy and Hydrocarbon Chemistry, Graduate School of Engineering, Kyoto \\ University, Kyoto 615-8510, Japan
}

${ }^{*}$ Correspondence should be addressed

Tel: +81-75-383-2491

Email: nishi.naoya.7e@kyoto-u.ac.jp

\begin{abstract}
The electrocapillarity and zero-frequency differential capacitance, $C_{\mathrm{d}}$, have been studied using pendant drop method, at the $\mathrm{Hg}$ interface of an ionic liquid (IL), 1-ethyl-3-methylimidazolium bis(trifluoromethanesulfonyl)amide, $\left[\mathrm{C}_{2} \mathrm{mim}^{+}\right]\left[\mathrm{TFSA}^{-}\right]$, and have been compared with those of $\left[\mathrm{C}_{2} \mathrm{mim}^{+}\right] \mathrm{BF}_{4}^{-}$, an IL with the common cation and a different anion, to focus on the anion dependence of zero-frequency $C_{\mathrm{d}}$. The $\mathrm{Hg}$ interface of $\left[\mathrm{C}_{2} \mathrm{mim}^{+}\right]\left[\mathrm{TFSA}^{-}\right]$, the IL of the larger anion in the present study, exhibits greater zero-frequency $C_{\mathrm{d}}$ than that of $\left[\mathrm{C}_{2} \mathrm{mim}^{+}\right] \mathrm{BF}_{4}^{-}$, the IL of the smaller anion. This behavior contradicts a simple expectation in which larger ion leads to smaller $C_{\mathrm{d}}$. This apparent contradiction is explained by proximity of the charged moiety of TFSAto the electrode surface compared with that of $\mathrm{BF}_{4}^{-}$. The potential dependence of zero-frequency $C_{\mathrm{d}}$ for the two ILs both exhibits one-hump camel shape around the potential of zero charge $\left(E_{\mathrm{pzc}}\right)$, which has been predicted to be specific behavior of the electrical double layer of ILs by theory and simulation. The humps are located at potentials more negative than $E_{\mathrm{pzc}}$. From a mean-field lattice-gas theory for the EDL in ILs, this negative shift can be interpreted that the charged moiety for $\mathrm{C}_{2} \mathrm{mim}^{+}$is more easily condensed in the EDL than those for $\mathrm{BF}_{4}^{-}$ and TFSA ${ }^{-}$.
\end{abstract}

Keywords: electric double layer; interfacial structure; interfacial tension; surface tension; electrochemical impedance spectroscopy; electrocapillary curve; slow dynamics; slow relaxation; hysteresis; TFSI 


\section{Introduction}

Ionic liquids (ILs) are liquid salts that are composed of cations and anions and the possible electrochemical applications of ILs have recently accelerated studies on the structure of the electrochemical interface of ILs. ${ }^{1-4}$ The differential capacitance $\left(C_{\mathrm{d}}\right)$ reflects the interfacial structure and its potential dependence, i.e., the behavior of ions in the electrical double layer (EDL). Since ILs are entirely composed of ions without neutral solvent molecules, the potential dependence of $C_{\mathrm{d}}$ has been predicted ${ }^{3,5,6}$ to be different from that of the Gouy-Chapman-Stern (GCS) model, ${ }^{7-9}$ which has successfully modeled the EDL for dilute electrolyte solutions where neutral solvent molecules are the major components. The mean-field lattice-gas model for the EDL in ILs proposed by Kornyshev ${ }^{5}$ illustrates the peculiar camel-shape potential dependence of $C_{\mathrm{d}}$ : either of one-hump or two-hump shape around the potential of zero charge $\left(E_{\mathrm{pzc}}\right)$ depending on the size of charged and neutral moieties of IL ions, ${ }^{10-13}$ in contrast to the U shape behavior for the GCS model. The one-hump camel shape is for ILs composed of small ions and can be explained by excluded volume not only between electrode and ions, but also between neighboring ions in the EDL, the latter of which was not taken into account in the GCS model. The two-hump camel shape is for ILs with relatively large ions having neutral moiety and is similar to the one-hump shape except around $E_{\mathrm{pzc}}$ where the potential dependence of $C_{\mathrm{d}}$ returns to the GCS behavior, showing negative curvature. This is due to the neutral moiety in IL ions that can play a role as "latent void" 10,11 to be replaced with charged moiety in IL ions at the first ionic layer when the interface becomes charged from $E_{\mathrm{pzc}}$.

Experimentally, $C_{\mathrm{d}}$ can be measured by using electrochemical impedance spectroscopy (EIS) at a frequency or a range of frequency and by adopting one of probable equivalent circuit models. The EIS $C_{\mathrm{d}}$ for the electrochemical interface of ILs has been intensively reported. ${ }^{14-24}$ However, the EIS $C_{\mathrm{d}}$ is known to have strong frequency dependence ${ }^{25-32}$ and also hysteresis effect, ${ }^{25,33-35}$ both of which seem to result from the structural ordering of IL interface ${ }^{36-42}$ and the ultraslow dynamics ${ }^{43-50}$ of such ordered structure. This makes it difficult to compare the EIS $C_{\mathrm{d}}$ with $C_{\mathrm{d}}$ from theory and simulation, latter of which is $C_{\mathrm{d}}$ in equilibrium, i.e., zero-frequency $C_{\mathrm{d}}$. This problem has been pointed out by Fedorov and Kornyshev in their recent review ${ }^{3}$ as "The fact that impedance measurements cannot reliably assess equilibrium characteristics is not a problem of the EDL theory that operates with equilibrium properties, but rather a problem of experimental techniques available these days." Therefore, the experimental method that can evaluate zero-frequency $C_{\mathrm{d}}$ would be desirable to compare experimental and theoretical zero-frequency $C_{\mathrm{d}}$, extract the characteristics of the EDL in ILs from the comparison, and furthermore provide feedbacks for the improvement of the theory of the EDL in ILs.

Recently, we experimentally obtained zero-frequency $C_{\mathrm{d}}$ from the thermodynamic analysis of the electrocapillarity (interfacial tension as a function of electrode potential) at the IL/Hg interface measured using the pendant drop method. ${ }^{51}$ Since the pendant drop method is a static method, the measurements are not affected by the ultraslow dynamics of the interfacial structure of ILs, enabling us to experimentally evaluate zero- 
frequency $C_{\mathrm{d}}$ and to directly compare it with the prediction by theory and simulation. It should be noted that similar methods to measure electrocapillarity such as drop time method ${ }^{15,52-57}$ and drop weight method ${ }^{58}$ pre- $^{-}$ viously reported for IL|Hg interface, are dynamic ones, which cannot escape from the slow dynamics problem. The potential dependence of zero-frequency $C_{\mathrm{d}}$ obtained using the pendant drop method exhibited remarkable dependence on alkyl chain length of IL cations. $\left[\mathrm{C}_{2} \mathrm{mim}^{+}\right] \mathrm{BF}_{4}^{-}, \mathrm{IL}$ of cation having short alkyl chain, showed the one-hump potential dependence, whereas $\left[\mathrm{C}_{8} \mathrm{mim}^{+}\right] \mathrm{BF}_{4}^{-}$with long alkyl chain, i.e., large neutral moiety, showed two-hump camel shape $\left(\mathrm{C}_{n} \mathrm{mim}^{+}\right.$: 1-alkyl-3-methylimidazolium). These findings experimentally proved the validity of the prediction by theory and simulation. $3,5,10$

In the present study, we further explore the dependence of zero-frequency $C_{\mathrm{d}}$ on ionic species of ILs, by studying the electrocapillarity and the zero-frequency $C_{\mathrm{d}}$ at the $\mathrm{Hg}$ interface of $\left[\mathrm{C}_{2} \mathrm{mim}^{+}\right]\left[\mathrm{TFSA}^{-}\right]\left(\mathrm{TFSA}^{-}\right.$; bis(trifluoromethanesulfonyl)amide) and by comparing them with those of $\left[\mathrm{C}_{2} \mathrm{mim}^{+}\right] \mathrm{BF}_{4}^{-}$previously studied by us. ${ }^{51}$ Although we previously used the mean-field lattice-gas theory for ILs composed of same size ions for analysis, in the present study we used an extended version of the theory recently proposed by Han and coworkers $^{59}$ where the size of IL ions can be different. The theory enables us to discuss the difference in the behavior of cation and anion in the EDL from the zero-frequency $C_{\mathrm{d}}$ data. TFSA ${ }^{-}$is one of the most frequently used IL anions and the behavior of $\left[\mathrm{C}_{2} \mathrm{mim}^{+}\right]\left[\mathrm{TFSA}^{-}\right]$at the electrode interface has been studied by experiment ${ }^{15,37,41,55,57,58,60,61}$ and simulation. ${ }^{62-66}$ TFSA $^{-}$has three-time larger volume than $\mathrm{BF}_{4}^{-}$(Table 1), and has asymmetric structure and localized charge distribution compared with $\mathrm{BF}_{4}^{-}$. We will discuss the effect of these difference of the molecular structure on the macroscopic zero-frequency $C_{\mathrm{d}}$ behavior.

\section{Experimental}

For the preparation of $\left[\mathrm{C}_{2} \mathrm{mim}^{+}\right]\left[\mathrm{TFSA}^{-}\right]$, equimolar amount of synthesized ${ }^{51}\left[\mathrm{C}_{2} \mathrm{mim}^{+}\right] \mathrm{Br}^{-}$and purchased $\mathrm{Li}^{+}\left[\mathrm{TFSA}^{-}\right]$(Central Glass Co.) were dissolved in water and $\left[\mathrm{C}_{2} \mathrm{mim}^{+}\right]\left[\mathrm{TFSA}^{-}\right]$in the aqueous solution was extracted to dichloromethane. Dry $\mathrm{Na}_{2} \mathrm{SO}_{4}$ and $\mathrm{MgSO}_{4}$ solids were added to the dichloromethane solution to remove water and the solids were then filtered off. $\left[\mathrm{C}_{2} \mathrm{mim}^{+}\right]\left[\mathrm{TFSA}^{-}\right]$dissolved in dichloromethane was purified by column chromatography with activated carbon and silica gel as the stationary phase. ${ }^{43,67}$ Dichloromethane was removed using an evaporator and a rotary oil pump, and $\left[\mathrm{C}_{2} \mathrm{mim}^{+}\right]\left[\mathrm{TFSA}^{-}\right]$was obtained as colorless liquid.

The details of the pendant drop method have been reported previously. ${ }^{51}$ A pendant drop of $\mathrm{Hg}$ hanging from a glass tube immersed in $\left[\mathrm{C}_{2} \mathrm{mim}^{+}\right]\left[\mathrm{TFSA}^{-}\right]$was illuminated and the shape of the $\mathrm{Hg}$ drop was imaged. The outline of the drop was fitted with the theoretical curve of Bashforth-Adams equation. In the fitting the densities, $\rho$, of the two liquids were fixed and the interfacial tension, $\sigma$, was evaluated from one of the variable parameters. ${ }^{51}$ The $\rho$ value for $\left[\mathrm{C}_{2} \mathrm{mim}^{+}\right]\left[\mathrm{TFSA}^{-}\right]$was measured to be $1.520 \mathrm{~g} \mathrm{~cm}^{-3}$ at $25.0{ }^{\circ} \mathrm{C}$ by using a density meter (DA-505, KEM), which agrees with literature values. ${ }^{68,69}$ The $\rho$ value for $\mathrm{Hg}$ was adopted to be $13.5336 \mathrm{~g} \mathrm{~cm}^{-3}$ at $25.0{ }^{\circ} \mathrm{C}$ from literature. ${ }^{70}$ The potential at the $\mathrm{IL} \mid \mathrm{Hg}$ interface was controlled 
with a three-electrode electrochemical system. $\mathrm{A} \mathrm{Ag}$ wire coated with $\mathrm{AgCl}$ was directly immersed in the IL as a quasi-reference electrode (QRE), and a Pt coiled wire as a counter electrode (CE). The potential of the $\mathrm{Hg}$ working electrode (WE) with respect to the $\mathrm{Ag} / \mathrm{AgCl} \mathrm{QRE}$, denoted as $E$, was controlled using a PCcontrolled potentiostat (HA1010mM1A, Hokuto Denko). At each potential, measurements were continued for sufficiently long time, typically more than $5 \mathrm{~min}$ to equilibrate the interfacial structure at the IL/Hg interface. ${ }^{51}$ The $\sigma$ value that became independent of time was adopted as $\sigma$ in equilibrium at the potential. Measurements were performed at $25.0 \pm 0.1{ }^{\circ} \mathrm{C}$. The surface charge density on $\mathrm{Hg}, q_{\mathrm{M}}$, was evaluated from the numerical differentiation of the $E$ dependence of $\sigma$ in the same manner as previously reported. ${ }^{51}$ Similarly, the zerofrequency $C_{\mathrm{d}}$ was evaluated from the numerical differentiation of the potential dependence of $q_{\mathrm{M}}$ with respect to $E$.

To compare with the zero-frequency $C_{\mathrm{d}}$, the EIS $C_{\mathrm{d}}$ was also measured. A hanging mercury drop electrode (WK2, Institute of Physical Chemistry Polish Academy of Sciences) was used as WE. The surface area of $\mathrm{Hg}, A$, was $0.024 \mathrm{~cm}^{2}$. QRE and CE are the same as those in the pendant drop method. The EIS measurements were performed with a PC-controlled potentiostat (CompactStat, Ivium Technologies) with the ac potential amplitude of $10 \mathrm{mV}$ and the frequency range from 10 to $1000 \mathrm{~Hz}$. For the analysis of impedance spectra we used equivalent circuit composed of constant phase element (CPE), whose impedance is $\frac{1}{(i \omega)^{p} T}$ where $\omega$ is angular frequency, in series with a solution resistance. When needed, an electron-transfer resistance was added in parallel with CPE. The EIS $C_{\mathrm{d}}$ was evaluated as

$$
C_{\mathrm{d}}=\frac{T \omega^{p-1}}{A}
$$

As shown in Eq.1, $C_{\mathrm{d}}$ of CPE depends on the frequency. As a representative data we chose $C_{\mathrm{d}}$ at $100 \mathrm{~Hz}$, which corresponds to the midpoint of the measurement frequency range in logarithmic scale. Before measurements at each dc potential, we applied the dc potential for 60-100 s to minimize the effect of the ultraslow dynamics of EDL.

\section{Results and Discussion}

The electrocapillary curve at the $\left[\mathrm{C}_{2} \mathrm{mim}^{+}\right]\left[\mathrm{TFSA}^{-}\right] \mid \mathrm{Hg}$ interface is shown in Fig.1 as solid circles. The shape of $\sigma$ as a function of $E$ is parabolic and the potential at the apex of the parabola around $-0.4 \mathrm{~V}$, is the potential of zero charge, $E_{\mathrm{pzc}}$, where the interface is not charged $\left(q_{\mathrm{M}}=0\right)$. In Fig.1 also shown is the electrocapillary curve at the $\left[\mathrm{C}_{2} \mathrm{mim}^{+}\right] \mathrm{BF}_{4}^{-} \mid \mathrm{Hg}$ interface (solid squares) from our previous study. ${ }^{51}$ The $\sigma$ value for $\left[\mathrm{C}_{2} \mathrm{mim}^{+}\right]\left[\mathrm{TFSA}^{-}\right]$at $E_{\mathrm{pzc}}, 355 \mathrm{mN} \mathrm{m}^{-1}$, which is $34 \mathrm{mN} \mathrm{m}^{-1}$ less than that for $\left[\mathrm{C}_{2} \mathrm{mim}^{+}\right] \mathrm{BF}_{4}^{-}$. The interfacial tensions of the free surface (IL/air interface) of the two ILs also have similar tendency: 35.63 $\mathrm{mN} \mathrm{m}{ }^{-1}$ for $\left[\mathrm{C}_{2} \mathrm{mim}^{+}\right]\left[\mathrm{TFSA}^{-}\right]$(measured by us) vs $54 \mathrm{mN} \mathrm{m}^{-1}$ for $\left[\mathrm{C}_{2} \mathrm{mim}^{+}\right] \mathrm{BF}_{4}^{-}{ }^{71}$ This tendency seems to be mainly due to the larger size of $\mathrm{TFSA}^{-}$compared with $\mathrm{BF}_{4}^{-}$(Table 1), leading to smaller surface ionic density and therefore smaller electrostatic attraction energy between neighboring cations and anions. This idea 
is supported by previous theoretical consideration of the surface tension of various high-temperature molten salts. ${ }^{72}$ One can also see in Fig. 1 that the curvature for $\left[\mathrm{C}_{2} \mathrm{mim}^{+}\right]\left[\mathrm{TFSA}^{-}\right]$is larger than that for $\left[\mathrm{C}_{2} \mathrm{mim}^{+}\right] \mathrm{BF}_{4}^{-}$, which means that the zero-frequency $C_{\mathrm{d}}$ for $\left[\mathrm{C}_{2} \mathrm{mim}^{+}\right]\left[\mathrm{TFSA}^{-}\right]$is larger than that for $\left[\mathrm{C}_{2} \mathrm{mim}^{+}\right] \mathrm{BF}_{4}^{-}$since $C_{\mathrm{d}}=-\left(\frac{\partial^{2} \sigma}{\partial E^{2}}\right)$. This tendency is counterintuitive, when we recall the Helmholtz model, ${ }^{73} C_{\mathrm{d}}=\frac{\epsilon}{r}$, where ions with greater radius, $r$, leads to smaller $C_{\mathrm{d}}$, taking into account $\epsilon$, static permittivity, of the two ILs are similar to each other. ${ }^{74}$ The negative charge of TFSA ${ }^{-}$is relatively localized on $\mathrm{N}$ and $\mathrm{O}$ atoms ${ }^{75}$ and TFSA ${ }^{-}$at the electrode interface can have an orientation in which the negative charge sites are close to the electrode surface. $^{76}$ In such orientation, $r$ should be small compared with the value simply expected from the ionic volume (Table 1). In contrast, $\mathrm{BF}_{4}^{-}$is symmetric and such orientation effect cannot be expected. This idea of charge distribution within anion explains the contradiction, greater $C_{\mathrm{d}}$ for larger TFSA ${ }^{-}$anion, observed above.

The $q_{\mathrm{M}}$ values were evaluated by the the numerical differentiation of $\sigma$ with respect to $E$. Fig. 2 shows the $q_{\mathrm{M}}$ values as a function of $E$ at the $\left[\mathrm{C}_{2} \mathrm{mim}^{+}\right]\left[\mathrm{TFSA}^{-}\right] \mid \mathrm{Hg}$ interface (solid circles) along with those at $\left[\mathrm{C}_{2} \mathrm{mim}^{+}\right] \mathrm{BF}_{4}^{-} \mid \mathrm{Hg}$ interface (solid squares). ${ }^{51}$ In addition to general trend that the $q_{\mathrm{M}}$ values increase at more positive potentials, one can find a non-monotonic increase in $q_{\mathrm{M}}$. Such a non-monotonic potential dependence of $q_{\mathrm{M}}$ reflects the potential dependence of the zero-frequency $C_{\mathrm{d}}$, since $C_{\mathrm{d}}=\left(\frac{\partial q_{\mathrm{M}}}{\partial E}\right)$. The slope of the plots for $\left[\mathrm{C}_{2} \mathrm{mim}^{+}\right]\left[\mathrm{TFSA}^{-}\right]$is greater than that for $\left[\mathrm{C}_{2} \mathrm{mim}^{+}\right] \mathrm{BF}_{4}^{-}$as a whole, indicating again that zero-frequency $C_{\mathrm{d}}$ is greater for $\left[\mathrm{C}_{2} \mathrm{mim}^{+}\right]\left[\mathrm{TFSA}^{-}\right]$. Inset in Fig.2 is a magnified figure of the $q_{\mathrm{M}}$ vs. $E$ plots around $q_{\mathrm{M}}=0$ to evaluate $E_{\mathrm{pzc}}$ by finding $E$ at $q_{\mathrm{M}}=0$. By using the local quadratic approximation around $q_{\mathrm{M}}=0, E_{\mathrm{pzc}}$ was evaluated to be $-0.373 \pm 0.002 \mathrm{~V}$ for the $\left[\mathrm{C}_{2} \mathrm{mim}^{+}\right]\left[\mathrm{TFSA}^{-}\right] \mid \mathrm{Hg}$ interface, while $E_{\mathrm{pzc}}$ for the $\left[\mathrm{C}_{2} \mathrm{mim}^{+}\right] \mathrm{BF}_{4}^{-} \mid \mathrm{Hg}$ interface was $-0.424 \pm 0.012 \mathrm{~V}$. The $E_{\mathrm{pzc}}$ data will play a key role as "reference" potential when we discuss the potential dependence of the zero-frequency $C_{\mathrm{d}}$ below.

The zero-frequency $C_{\mathrm{d}}$ values were evaluated by the numerical differentiation of $q_{\mathrm{M}}$. Fig. 3 shows zerofrequency $C_{\mathrm{d}}$ for the $\left[\mathrm{C}_{2} \mathrm{mim}^{+}\right]\left[\mathrm{TFSA}^{-}\right] \mid \mathrm{Hg}$ interface (solid circles in Fig. $3 \mathrm{a}$ ) and $\left[\mathrm{C}_{2} \mathrm{mim}^{+}\right] \mathrm{BF}_{4}^{-} \mid \mathrm{Hg}$ interface (solid squares in Fig. $3 \mathrm{~b})^{51}$ with the vertical dotted lines at $E_{\mathrm{pzc}}$. One can notice several features from the data. Firstly, for both the ILs, the zero-frequency $C_{\mathrm{d}}$ exhibits one-hump camel-shape potential dependence that has a local maximum near $E_{\mathrm{pzc}}$. Such a local maximum around $E_{\mathrm{pzc}}$ is opposite to the global minimum at $E_{\mathrm{pzc}}$ predicted from GCS model but agrees with the prediction by recent theories for the EDL of ILs as explained in Introduction. $3,5,6$ Secondly, the local maximum of the zero-frequency $C_{\mathrm{d}}$ is more negative than $E_{\mathrm{pzc}}$ for both the ILs. The shift is the symptom of ion-size asymmetry, as suggested from theory ${ }^{5,59,77-79}$ and simulation; ${ }^{78,80-82}$ i.e., when the anion is larger than cation, the local maximum shifts negatively. If we simply refer to ionic volume (Table 1) this negative shift agrees for the $\left[\mathrm{C}_{2} \mathrm{mim}^{+}\right]\left[\mathrm{TFSA}^{-}\right]$case but disagrees for the $\left[\mathrm{C}_{2} \mathrm{mim}^{+}\right] \mathrm{BF}_{4}^{-}$case. This point will be discussed below with fitting results. Thirdly, the local maximum value of the zero-frequency $C_{\mathrm{d}}$ for $\left[\mathrm{C}_{2} \mathrm{mim}^{+}\right]\left[\mathrm{TFSA}^{-}\right]$is higher than $\left[\mathrm{C}_{2} \mathrm{mim}^{+}\right] \mathrm{BF}_{4}^{-}$, as was seen in the curvature of the electrocapillarity in Fig.1 and the slope of the $q_{\mathrm{M}}$ plots in Fig.2. Fourthly, far from the local maximum, i.e., at $E \gg E_{\mathrm{pzc}}$, the zero-frequency $C_{\mathrm{d}}$ increases. This "wing" phenomenon was also observed at the aque- 
ous solution| $\mathrm{Hg}$ interface ${ }^{83}$ and in our previous study at the $\mathrm{IL} \mid \mathrm{Hg}$ interface. ${ }^{51}$ For the $\mathrm{IL} \mid \mathrm{Hg}$ interface, the results of in-situ spectroscopic ellipsometry suggest that this increase in the zero-frequency $C_{\mathrm{d}}$ is likely due to densification of the ionic layers in the EDL. ${ }^{51,84}$

The EIS $C_{\mathrm{d}}$ is also shown in Fig. 3 as open symbols for comparison. The EIS $C_{\mathrm{d}}$ increases with increase in the potential and this tendency agrees with previous studies, ${ }^{15,55,57,60}$ although the EIS $C_{\mathrm{d}}$ values are different possibly due to frequency dependence or hysteresis effect, inherent to the EDL in ILs as described in Introduction. One can see smaller EIS $C_{\mathrm{d}}$ compared with zero-frequency $C_{\mathrm{d}}$ for both the two ILs. The smaller EIS $C_{\mathrm{d}}$ indicates that the EDL of ILs cannot fully be charged during a.c. potential perturbation and that slow components of $C_{\mathrm{d}}$ cannot be captured by EIS. The potential dependence of the EIS $C_{\mathrm{d}}$ is more gradual than that of zero-frequency $C_{\mathrm{d}}$ and does not have one-hump shape around $E_{\mathrm{pzc}}$. This gradual behavior is likely to be caused by slow exchange of ions in the EDL, suggested by studies using surface plasmon resonance ${ }^{47}$ and surface-enhanced IR absorption spectroscopy ${ }^{85}$ at IL|Au interface. The wing at $E \gg E_{\mathrm{pzc}}$ is not observed in the EIS $C_{\mathrm{d}}$ as well. The densification of the ionic layers in the EDL is also likely to decelerate ionic rearrangement, resulting in a large discrepancy between the EIS $C_{\mathrm{d}}$ and the zero-frequency $C_{\mathrm{d}}$.

To quantitatively analyze the potential dependence of zero-frequency $C_{\mathrm{d}}$, we used an analytical equation from recent mean-field lattice-gas theory for ILs composed of size-asymmetric ions: ${ }^{59}$

$$
\begin{aligned}
\frac{C_{\mathrm{d}}}{C_{\mathrm{d}, 0}}= & -\exp \left(-u_{0}\right)+\exp \left(u_{0}\right)\left[\frac{\xi \exp \left(u_{0}\right)+\eta}{\xi+\eta}\right]^{\frac{1}{\xi}-1} \mid \\
& \times\left[\sqrt{2 \gamma_{\mathrm{C}}}\left\{\exp \left(-u_{0}\right)+(\xi+\eta)\left[\frac{\xi \exp \left(u_{0}\right)+\eta}{\xi+\eta}\right]^{\frac{1}{\xi}}\right\}\right. \\
& \times \sqrt{\left.\ln \left\{\exp \left(-u_{0}\right)+(\xi+\eta)\left[\frac{\xi \exp \left(u_{0}\right)+\eta}{\xi+\eta}\right]^{\frac{1}{\xi}}\right\}+\ln \left(\frac{\gamma_{\mathrm{C}}}{2}\right)\right]^{-1}}
\end{aligned}
$$

with

$$
\begin{aligned}
& \xi=\frac{\gamma_{\mathrm{A}}}{\gamma_{\mathrm{C}}} \\
& \eta=\frac{2}{\gamma_{\mathrm{C}}}-1-\xi
\end{aligned}
$$

where $C_{\mathrm{d}} / C_{\mathrm{d}, 0}$ is the normalized zero-frequency $C_{\mathrm{d}}$ and $u_{0}=\frac{F\left(E-E_{\mathrm{prc}}\right)}{R T}$ is the normalized potential with the Faraday constant $F$, the gas constant $R$, and the absolute temperature $T$. Here the compacity, $\gamma_{\mathrm{i}}$, of the ion $\mathrm{i}$ ( $\mathrm{i}=\mathrm{C}$ for cation and $\mathrm{A}$ for anion) is

$$
\gamma_{\mathrm{i}}=\frac{c_{\text {bulk }}}{c_{\mathrm{i}, \max }}
$$

where $c_{\text {bulk }}$ is the concentration of ions in bulk (note that this is twice the concentration of the cation or the anion in bulk) and $c_{\mathrm{i}, \max }$ is the maximum local possible concentration of the charged moiety of the ion i. ILs having large neutral moiety such as $\left[\mathrm{C}_{8} \mathrm{mim}^{+}\right]\left[\mathrm{BF}_{4}^{-}\right]$have small compacity, which leads to two-hump potential dependence of zero-frequency $C_{\mathrm{d}}{ }^{51}$ On the other hand, one-hump behavior observed in the present study implies that $\gamma_{\mathrm{i}}$ is relatively large for the ions in the two ILs. 
The Eq. 2 from the mean-field lattice-gas theory include steric effect between ions but does not include another important feature of the EDL in ILs: overscreening effect. ${ }^{5}$ Models taking into account the overscreening effect have been proposed ${ }^{86}$ and intensively studied. ${ }^{87-90}$ Very recently, a perturbation-theory approach to develop an extended version of the mean-field lattice-gas theory that takes into account short-range correlation between ions has also been presented. ${ }^{91}$ The mean-field theory without the overscreening effect has been found to overestimate $C_{\mathrm{d}} \cdot{ }^{86}$ However, the "overestimation coefficient", the extent of the overestimation, is almost constant within the potential range not far from $E_{\mathrm{pzc}}$, up to around a few hundred $\mathrm{mV} .{ }^{86}$ With $C_{\mathrm{d}, 0}$ as a scaling parameter, we still can discuss the potential dependence of our experimental zero-frequency $C_{\mathrm{d}}$ by using Eq.2.

We fitted Eq.2 to the experimental data for the potential dependence of zero-frequency $C_{\mathrm{d}}$. We limited the fitting region around $E_{\mathrm{pzc}}$ because at potentials far from $E_{\mathrm{pzc}}$ the wing effect (rise of zero-frequency $C_{\mathrm{d}}$ ) is observed and the cause, which is the densification of ionic layers, is not taken into account in the theory. The fitting parameters are $\gamma_{\mathrm{C}}, \gamma_{\mathrm{A}}$, and $C_{\mathrm{d}, 0}$, with the fixed parameter of $E_{\mathrm{pzc}}$ obtained in Fig.2. The fitted curves are shown in Fig. 3 as dashed lines and the fitted parameters are listed in Table 2. The $C_{\mathrm{d}, 0}$ value for $\left[\mathrm{C}_{2} \mathrm{mim}^{+}\right]\left[\mathrm{TFSA}^{-}\right], 57 \mu \mathrm{F} \mathrm{cm}{ }^{-2}$, is 1.7 times higher than that for $\left[\mathrm{C}_{2} \mathrm{mim}^{+}\right] \mathrm{BF}_{4}^{-}, 34 \mu \mathrm{F} \mathrm{cm}{ }^{-2}$, again, which can be explained by the asymmetry of the $\mathrm{TFSA}^{-}$shape. The $\gamma_{\mathrm{i}}$ values for $\left[\mathrm{C}_{2} \mathrm{mim}^{+}\right]\left[\mathrm{TFSA}^{-}\right]$are similar to or slightly smaller than those for $\left[\mathrm{C}_{2} \mathrm{mim}^{+}\right] \mathrm{BF}_{4}^{-}$, indicating that "compacity" of ions in these ILs is similar. Although TFSA ${ }^{-}$has three-time larger volume than $\mathrm{BF}_{4}^{-}$, the charged moiety of TFSA ${ }^{-}$cannot be condensed in the EDL significantly more than $\mathrm{BF}_{4}^{-}$. In other words, the neutral moiety of TFSA ${ }^{-}$, if exists, cannot play a role as "latent void" in the EDL. The $\gamma_{\mathrm{C}}$ value is lower than $\gamma_{\mathrm{A}}$ for both the ILs, which means smaller size for the charged moiety of $\mathrm{C}_{2} \mathrm{mim}^{+}$than $\mathrm{TFSA}^{-}$and $\mathrm{BF}_{4}^{-}$. Quantitatively, the size ratio of the charged moieties between cation and anion is obtained from $\xi=\gamma_{\mathrm{A}} / \gamma_{\mathrm{C}}$ and is listed in Table 2. To compare with $\xi$, we also estimated the ionic volume, $V_{\mathrm{i}}$ (the sum of the charged and neutral moieties) by using quantum chemical calculation. The ionic volumes for ions are listed in Table 1 and the ratio, $V_{\mathrm{A}} / V_{\mathrm{C}}$, is in Table 2 . The $V_{\mathrm{i}}$ value for $\mathrm{C}_{2} \mathrm{mim}^{+}$is smaller than that for TFSA ${ }^{-}$, which accords with $\xi=2.1>1$ for $\left[\mathrm{C}_{2} \mathrm{mim}^{+}\right]\left[\mathrm{TFSA}^{-}\right]$. On the other hand, it is larger than that for $\mathrm{BF}_{4}^{-}$, opposite tendency to the size of the charged moiety for the two ions. This might indicate that $\mathrm{C}_{2} \mathrm{mim}^{+}$has relatively big neutral moiety and small charged moiety. However, such small volume of the charged moiety is unreasonable because the positive charge of $\mathrm{C}_{2} \mathrm{mim}^{+}$is delocalized over the imidazolium ring, major part of $\mathrm{C}_{2} \mathrm{mim}^{+}$structure. Factors missed in the mean-field lattice-gas model include orientation of IL ions at the interface. Several experimental ${ }^{85,92,93}$ and simulation ${ }^{94-97}$ studies have revealed that $\mathrm{C}_{n} \mathrm{mim}^{+}$cations in ILs at the electrode interface have preferential orientation which depends on the potential and the IL kinds. The orientation and its potential dependence are expected to affect the zerofrequency $C_{\mathrm{d}}$ behavior, although it is still unclear how they affect, due to the lack of available theory. To clarify the effect of the ionic orientation on zero-frequency $C_{\mathrm{d}}$ behavior, MD simulation for the EDL at the IL $\mid \mathrm{Hg}$ interface would be desirable as has been performed for the EDL at aqueous solution|Hg interface..$^{98}$ 


\section{Conclusions}

We evaluated and compared the zero-frequency $C_{\mathrm{d}}$ and its potential dependence for the EDL at the $\mathrm{Hg}$ interfaces of two ILs, $\left[\mathrm{C}_{2} \mathrm{mim}^{+}\right]\left[\right.$TFSA $\left.{ }^{-}\right]$and $\left[\mathrm{C}_{2} \mathrm{mim}^{+}\right] \mathrm{BF}_{4}^{-}$by using pendant drop method. This method enables us to overcome strong frequency dependence and hysteresis effect of $C_{\mathrm{d}}$ at the interface of ILs and therefore to directly compare the $C_{\mathrm{d}}$ behaviors of the two ILs each other and also compare them with the recently proposed EDL theory for ILs. The usage of $\mathrm{Hg}$, a liquid metal, is another advantage since otherwise we need to significantly consider crystal planes of solid metal surface and long-term contamination hysteresis, although we may keep in mind possible chemical interactions between $\mathrm{Hg}$ surface and IL ions. The zero-frequency $C_{\mathrm{d}}$ for $\left[\mathrm{C}_{2} \mathrm{mim}^{+}\right]\left[\mathrm{TFSA}^{-}\right]$is distinctly higher than that for $\left[\mathrm{C}_{2} \mathrm{mim}^{+}\right] \mathrm{BF}_{4}^{-}$despite larger $\mathrm{TFSA}^{-}$size than $\mathrm{BF}_{4}^{-}$. This counterintuitive result is explained by the localized negative charge of $\mathrm{TFSA}^{-}$, leading to the formation of thinner EDL than $\mathrm{BF}_{4}^{-}$. Comparison of the zero-frequency $C_{\mathrm{d}}$ with the mean-field lattice-gas theory suggests that $\mathrm{C}_{2} \mathrm{mim}^{+}$is more easily condensed in the EDL than either of $\mathrm{TFSA}^{-}$or $\mathrm{BF}_{4}^{-}$. This suggestion cannot be rationalized only by the volume of the charged and neutral moieties of the ions, implying that the orientation of ions is one of the essential factors to determine the zero-frequency $C_{\mathrm{d}}$ behavior.

\section{Acknowledgements}

This work was partly supported by a Grant-in-Aid for Scientific Research (Nos. 26410149, 26248004,16H04216). 
Table 1: Volume of ions by quantum chemical calculation in the level of B3LYP/6-311++G**.

\begin{tabular}{ll} 
Ion & $\begin{array}{l}V_{\mathrm{i}} \\
\left(\mathrm{cm}^{3} \mathrm{~mol}^{-1}\right)\end{array}$ \\
\hline $\mathrm{TFSA}^{-}$ & $123^{a}, 128^{b}$ \\
$\frac{\mathrm{BF}_{4}^{-}}{\mathrm{C}_{2} \mathrm{mim}^{+}} \quad 88$ \\
\hline$C_{1}$ conformer. $^{b} C_{2}$ conformer.
\end{tabular}

Table 2: Parameters for the fitting in Fig.3 using Eq.2.

\begin{tabular}{lllllll}
\hline $\mathrm{IL}$ & $\begin{array}{l}C_{0} \\
\left(\mu \mathrm{F} \mathrm{cm}{ }^{-2}\right)\end{array}$ & \multicolumn{1}{c}{$\gamma_{\mathrm{C}}$} & $\gamma_{\mathrm{A}}$ & $\begin{array}{c}E_{\mathrm{pzc}} \\
(\mathrm{V})\end{array}$ & $\xi\left(=\gamma_{\mathrm{A}} / \gamma_{\mathrm{C}}\right)$ & $V_{\mathrm{A}} / V_{\mathrm{C}}{ }^{a}$ \\
\hline$\left[\mathrm{C}_{2} \mathrm{mim}^{+}\right]\left[\mathrm{TFSA}^{-}\right]$ & $57 \pm 3$ & $0.23 \pm 0.03$ & $0.48 \pm 0.06$ & $-0.373^{b}$ & $2.1 \pm 0.2$ & 1.4 \\
{$\left[\mathrm{C}_{2} \mathrm{mim}^{+}\right]\left[\mathrm{BF}_{4}^{-}\right]$} & $34 \pm 3$ & $0.30 \pm 0.07$ & $0.50 \pm 0.14$ & $-0.424^{b}$ & $1.7 \pm 0.4$ & 0.51 \\
\hline \multicolumn{7}{c}{ Calculated from $V_{\mathrm{i}}$ in Table 1. ${ }^{b}$ Fixed to the value evaluated from Fig.2. }
\end{tabular}




\section{References}

(1) M. Armand, F. Endres, D. R. Macfarlane, H. Ohno, and B. Scrosati, Nat. Mater, 2009, 8, 621-629.

(2) ed. H. Ohno, Electrochemical Aspects of Ionic Liquids, Wiley, Hoboken, 2nd ed., 2011.

(3) M. V. Fedorov and A. A. Kornyshev, Chem. Rev., 2014, 114, 2978-3036.

(4) R. Hayes, G. G. Warr, and R. Atkin, Chem. Rev., 2015, 115, 6357-6426.

(5) A. A. Kornyshev, J. Phys. Chem. B, 2007, 111, 5545-5557.

(6) K. B. Oldham, J. Electroanal. Chem., 2008, 613, 131-138.

(7) L. G. Gouy, J. Phys., 1910, 9, 457-468.

(8) D. L. Chapman, Phil. Mag., 1913, 25, 475-481.

(9) O. Stern, Z. Elektrochem., 1924, 30, 508-516.

(10) M. V. Fedorov, N. Georgi, and A. A. Kornyshev, Electrochem. Commun., 2010, 12, 296-299.

(11) N. Georgi, A. A. Kornyshev, and M. V. Fedorov, J. Electroanal. Chem., 2010, 649, 261-267.

(12) M. Trulsson, J. Algotsson, J. Forsman, and C. E. Woodward, J. Phys. Chem. Lett., 2010, 1, 1191-1195.

(13) W. Silvestre-Alcantara, M. Kaja, D. Henderson, S. Lamperski, and L. B. Bhuiyan, Mol. Phys., 2016, 114, $53-60$.

(14) R. J. Gale and R. A. Osteryoung, Electrochim. Acta, 1980, 25, 1527-1529.

(15) C. Nanjundiah, S. F. McDevitt, and V. R. Koch, J. Electrochem. Soc., 1997, 144, 3392-3397.

(16) M. T. Alam, M. M. Islam, T. Okajima, and T. Ohsaka, Electrochem. Commun., 2007, 9, 2370-2374.

(17) M. M. Islam, M. T. Alam, and T. Ohsaka, J. Phys. Chem. C, 2008, 112, 16568-16574.

(18) M. M. Islam, M. T. Alam, T. Okajima, and T. Ohsaka, J. Phys. Chem. C, 2009, 113, 3386-3389.

(19) Y. Z. Su, Y. C. Fu, J. W. Yan, Z. B. Chen, and B. W. Mao, Angew. Chem.-Int. Edit., 2009, 48, 5148-5151.

(20) B. Bozzini, A. Bund, B. Busson, C. Humbert, A. Ispas, C. Mele, and A. Tadjeddine, Electrochem. Commun., 2010, 12, 56-60.

(21) J. P. Zheng, P. C. Goonetilleke, C. M. Pettit, and D. Roy, Talanta, 2010, 81, 1045-1055.

(22) L. Siinor, K. Lust, and E. Lust, J. Electrochem. Soc., 2010, 157, F83-F87.

(23) T. F. Esterle, D. Sun, M. R. Roberts, P. N. Bartlett, and J. R. Owen, Phys. Chem. Chem. Phys., 2012, 14, 3872-3881. 
(24) Q. Zhang, Y. Han, Y. Wang, S. Ye, and T. Yan, Electrochem. Commun., 2014, 38, 44-46.

(25) V. Lockett, R. Sedev, J. Ralston, M. Horne, and T. Rodopoulos, J. Phys. Chem. C, 2008, 112, 7486-7495.

(26) M. Gnahm, T. Pajkossy, and D. M. Kolb, Electrochim. Acta, 2010, 55, 6212-6217.

(27) M. Drüschler, B. Huber, and B. Roling, J. Phys. Chem. C, 2011, 115, 6802-6808.

(28) T. Pajkossy and D. M. Kolb, Electrochem. Commun., 2011, 13, 284-286.

(29) B. Roling, M. Drüschler, and B. Huber, Faraday Discuss., 2012, 154, 303-311.

(30) Y. Su, J. Yan, M. Li, M. Zhang, and B. Mao, J. Phys. Chem. C, 2013, 117, 205-212.

(31) L. Siinor, R. Arendi, K. Lust, and E. Lust, J. Electroanal. Chem., 2013, 689, 51-56.

(32) J. Wallauer, M. Drüschler, B. Huber, and B. Roling, Z. Naturforsch. B, 2013, 68, 1143-1153.

(33) T. R. Gore, T. Bond, W. Zhang, R. W. J. Scott, and I. J. Burgess, Electrochem. Commun., 2010, 12, $1340-1343$.

(34) M. Drüschler, B. Huber, S. Passerini, and B. Roling, J. Phys. Chem. C, 2010, 114, 3614-3617.

(35) M. T. Alam, J. Masud, M. M. Islam, T. Okajima, and T. Ohsaka, J. Phys. Chem. C, 2011, 115, 1979719804.

(36) M. Mezger, H. Schröder, H. Reichert, S. Schramm, J. S. Okasinski, S. Schöder, V. Honkimäki, M. Deutsch, B. M. Ocko, J. Ralston, M. Rohwerder, M. Stratmann, and H. Dosch, Science, 2008, 322, $424-428$

(37) R. Atkin, S. Z. El Abedin, R. Hayes, L. H. S. Gasparotto, N. Borisenko, and F. Endres, J. Phys. Chem. C, 2009, 113, 13266-13272.

(38) N. Nishi, Y. Yasui, T. Uruga, H. Tanida, T. Yamada, S. Nakayama, H. Matsuoka, and T. Kakiuchi, J. Chem. Phys., 2010, 132, 164705(1-6).

(39) N. Nishi, T. Uruga, H. Tanida, and T. Kakiuchi, Langmuir, 2011, 27, 7531-7536.

(40) N. Nishi, K. Kasuya, and T. Kakiuchi, J. Phys. Chem. C, 2012, 116, 5097-5102.

(41) J. M. Black, M. B. Okatan, G. Feng, P. T. Cummings, S. V. Kalinin, and N. Balke, Nano Energy, 2015, $15,737-745$

(42) N. Nishi, T. Uruga, and H. Tanida, J. Electroanal. Chem., 2015, 759, 129-136.

(43) Y. Yasui, Y. Kitazumi, R. Ishimatsu, N. Nishi, and T. Kakiuchi, J. Phys. Chem. B, 2009, 113, 3273-3276.

(44) I. Bou-Malham and L. Bureau, Soft Matter, 2010, 6, 4062-4065. 
(45) S. Makino, Y. Kitazumi, N. Nishi, and T. Kakiuchi, Electrochem. Commun., 2011, 13, 1365-1368.

(46) M. Drüschler, N. Borisenko, J. Wallauer, C. Winter, B. Huber, F. Endres, and B. Roling, Phys. Chem. Chem. Phys., 2012, 14, 5090-5099.

(47) N. Nishi, Y. Hirano, T. Motokawa, and T. Kakiuchi, Phys. Chem. Chem. Phys., 2013, 15, 11615-11619.

(48) A. Uysal, H. Zhou, G. Feng, S. S. Lee, S. Li, P. Fenter, P. T. Cummings, P. F. Fulvio, S. Dai, J. K. McDonough, and Y. Gogotsi, J. Phys. Chem. C, 2014, 118, 569-574.

(49) A. Uysal, H. Zhou, G. Feng, S. S. Lee, S. Li, P. T. Cummings, P. F. Fulvio, S. Dai, J. K. McDonough, Y. Gogotsi, and P. Fenter, J. Phys.-Condes. Matter, 2015, 27, 032101(1-9).

(50) T. Jaensch, J. Wallauer, and B. Roling, J. Phys. Chem. C, 2015, 119, 4620-4626.

(51) N. Nishi, A. Hashimoto, E. Minami, and T. Sakka, Phys. Chem. Chem. Phys., 2015, 17, 5219-5226.

(52) M. M. Islam, M. T. Alam, T. Okajima, and T. Ohsaka, J. Phys. Chem. B, 2007, 111, 12849-12856.

(53) F. Silva, C. Gomes, M. Figueiredo, R. Costa, A. Martins, and C. M. Pereira, J. Electroanal. Chem., 2008, 622, 153-160.

(54) M. T. Alam, M. M. Islam, T. Okajima, and T. Ohsaka, J. Phys. Chem. C, 2009, 113, 6596-6601.

(55) R. Costa, C. M. Pereira, and F. Silva, Phys. Chem. Chem. Phys., 2010, 12, 11125-11132.

(56) M. Ammam, D. Di Caprio, and L. Gaillon, Electrochim. Acta, 2012, 61, 207-215.

(57) R. Costa, C. M. Pereira, and F. Silva, RSC Adv., 2013, 3, 11697-11706.

(58) A. Lewandowski, T. Majkowski, and M. Galiński, Z. Naturfors., 2009, 64a, 263-268.

(59) Y. Han, S. Huang, and T. Yan, J. Phys.-Condes. Matter, 2014, 26, 284103(1-10).

(60) R. Costa, C. M. Pereira, and A. Fernando Silva, Electrochem. Commun., 2015, 57, 10-13.

(61) A. Elbourne, S. McDonald, K. Voichovsky, F. Endres, G. G. Warr, and R. Atkin, ACS Nano, 2015, 9, $7608-7620$.

(62) G. Feng and P. T. Cummings, J. Phys. Chem. Lett., 2011, 2, 2859-2864.

(63) G. Feng, D.-e. Jiang, and P. T. Cummings, J. Chem. Theory Comput., 2012, 8, 1058-1063.

(64) J. Vatamanu, O. Borodin, D. Bedrov, and G. D. Smith, J. Phys. Chem. C, 2012, 116, 7940-7951.

(65) Z. Hu, J. Vatamanu, O. Borodin, and D. Bedrov, Electrochim. Acta, 2014, 145, 40-52.

(66) G. Feng, S. Li, W. Zhao, and P. T. Cummings, AICHE J., 2015, 61, 3022-3028. 
(67) M. J. Earle, C. M. Gordon, N. V. Plechkova, K. R. Seddon, and T. Welton, Anal. Chem., 2007, 79, 758764.

(68) S. Dzyuba and R. Bartsch, ChemPhysChem, 2002, 3, 161-166.

(69) A. Wandschneider, J. K. Lehmann, and A. Heintz, J. Chem. Eng. Data, 2008, 53, 596-599.

(70) D. Ambrose, Metrologia, 1990, 27, 245-247.

(71) M. Tariq, M. G. Freire, B. Saramago, J. A. P. Coutinho, J. N. Canongia Lopes, and L. P. N. Rebelo, Chem. Soc. Rev., 2012, 41, 829-868.

(72) K. Yajima, H. Moriyama, and J. Oishi, J. Phys. Chem., 1984, 88, 4390-4394.

(73) H. Helmholtz, Ann. Phys. Chem., 1853, 165, 211-233.

(74) H. Weingaertner, Z. Phys. Chem., 2006, 220, 1395-1405.

(75) J. Lopes and A. Padua, J. Phys. Chem. B, 2004, 108, 16893-16898.

(76) J. Vatamanu, O. Borodin, and G. D. Smith, J. Am. Chem. Soc., 2010, 132, 14825-14833.

(77) D.-e. Jiang, D. Meng, and J. Wu, Chem. Phys. Lett., 2011, 504, 153-158.

(78) S. Lamperski, J. Sosnowska, L. B. Bhuiyan, and D. Henderson, J. Chem. Phys., 2014, 140, 014704(1-4).

(79) A. C. Maggs and R. Podgornik, Soft Matter, 2016, 12, 1219-1229.

(80) M. V. Fedorov and A. A. Kornyshev, J. Phys. Chem. B, 2008, 112, 11868-11872.

(81) M. Kaja, W. Silvestre-Alcantara, S. Lamperski, D. Henderson, and L. B. Bhuiyan, Mol. Phys., 2015, 113, 1043-1052.

(82) V. Ivaništšev, K. Kirchner, T. Kirchner, and M. V. Fedorov, J. Phys.-Condes. Matter, 2015, 27, 102101(15).

(83) D. C. Grahame, Chem. Rev., 1947, 41, 441-501.

(84) N. Nishi, J. Uchiyashiki, R. Oogami, and T. Sakka, Thin Solid Films, 2014, 571, 735-738.

(85) K. Motobayashi, K. Minami, N. Nishi, T. Sakka, and M. Osawa, J. Phys. Chem. Lett., 2013, 4, 3110-3114.

(86) M. Z. Bazant, B. D. Storey, and A. A. Kornyshev, Phys. Rev. Lett., 2011, 106, 046102(1-4).

(87) G. Feng, J. Huang, B. G. Sumpter, V. Meunier, and R. Qiao, Phys. Chem. Chem. Phys., 2011, 13, 1472314734.

(88) H. Zhao, Phys. Rev. E, 2011, 84, 051504(1-10). 
(89) V. Demery, D. S. Dean, T. C. Hammant, R. R. Horgan, and R. Podgornik, EPL, 2012, 97, 28004(1-5).

(90) A. Yochelis, M. B. Singh, and I. Visoly-Fisher, Chem. Mat., 2015, 27, 4169-4179.

(91) Z. A. Goodwin, G. Feng, and A. A. Kornyshev, Electrochim. Acta, 2017, 225, 190-197.

(92) S. Rivera-Rubero and S. Baldelli, J. Phys. Chem. B, 2004, 108, 15133-15140.

(93) N. Nanbu, T. Kato, Y. Sasaki, and F. Kitamura, Electrochemistry, 2005, 73, 610-613.

(94) C. Pinilla, M. Del Popolo, R. Lynden-Bell, and J. Kohanoff, J. Phys. Chem. B, 2005, 109, 17922-17927.

(95) S. A. Kislenko, I. S. Samoylov, and R. H. Amirov, Phys. Chem. Chem. Phys., 2009, 11, 5584-5590.

(96) S. Wang, S. Li, Z. Cao, and T. Yan, J. Phys. Chem. C, 2010, 114, 990-995.

(97) X. Si, S. Li, Y. Wang, S. Ye, and T. Yan, ChemPhysChem, 2012, 13, 1671-1676.

(98) D. Dimitrov, N. Raev, and K. Semerdzhiev, Phys. Chem. Chem. Phys., 2001, 3, 448-452. 


\section{Figure captions}

Fig. 1 Electrocapillarity at the $\left[\mathrm{C}_{2} \mathrm{mim}^{+}\right]\left[\mathrm{TFSA}^{-}\right] \mid \mathrm{Hg}$ interface (red solid circles) and at the $\left[\mathrm{C}_{2} \mathrm{mim}^{+}\right] \mathrm{BF}_{4}^{-} \mid \mathrm{Hg}$ interface (blue solid squares) ${ }^{[51]}$ measured by pendant drop method with error bars of one standard deviation.

Fig. 2 Surface charge density on $\mathrm{Hg}\left(q_{\mathrm{M}}\right)$ as a function of the electrode potential at the $\left[\mathrm{C}_{2} \mathrm{mim}^{+}\right]\left[\mathrm{TFSA}^{-}\right] \mid \mathrm{Hg}$ interface (red solid circles) and at the $\left[\mathrm{C}_{2} \mathrm{mim}^{+}\right] \mathrm{BF}_{4}^{-} \mid \mathrm{Hg}$ interface (blue solid squares) ${ }^{[51]}$ with error bars of one standard deviation. Inset is a magnified one around $q_{\mathrm{M}}=0$ for the $\left[\mathrm{C}_{2} \mathrm{mim}^{+}\right]\left[\mathrm{TFSA}{ }^{-}\right] \mathrm{Hg}$ interface. The solid curve in the inset is from quadratic least squares regression with weights for four consecutive data points around $q_{\mathrm{M}}=0$, which evaluated $E_{\mathrm{pzc}}$ to be $-0.373 \pm 0.002 \mathrm{~V}$.

Fig. 3 Zero-frequency differential capacitance as a function of the electrode potential (a) at the $\left[\mathrm{C}_{2} \mathrm{mim}^{+}\right]\left[\mathrm{TFSA}^{-}\right] \mid \mathrm{Hg}$ interface (red solid circles) and (b) at the $\left[\mathrm{C}_{2} \mathrm{mim}^{+}\right] \mathrm{BF}_{4}^{-} \mid \mathrm{Hg}$ interface (blue solid squares) ${ }^{[51]}$ with error bars of one standard deviation. Vertical dotted lines are at the potential of zero charge. The open circles and squares are differential capacitance at $100 \mathrm{~Hz}$ measured using EIS. The dashed lines are a fitted curve of Eq. 2 to experimental plots within the potential region (a) from -0.7 to $-0.2 \mathrm{~V}$ and (b) from -0.55 to $-0.15 \mathrm{~V}$. 


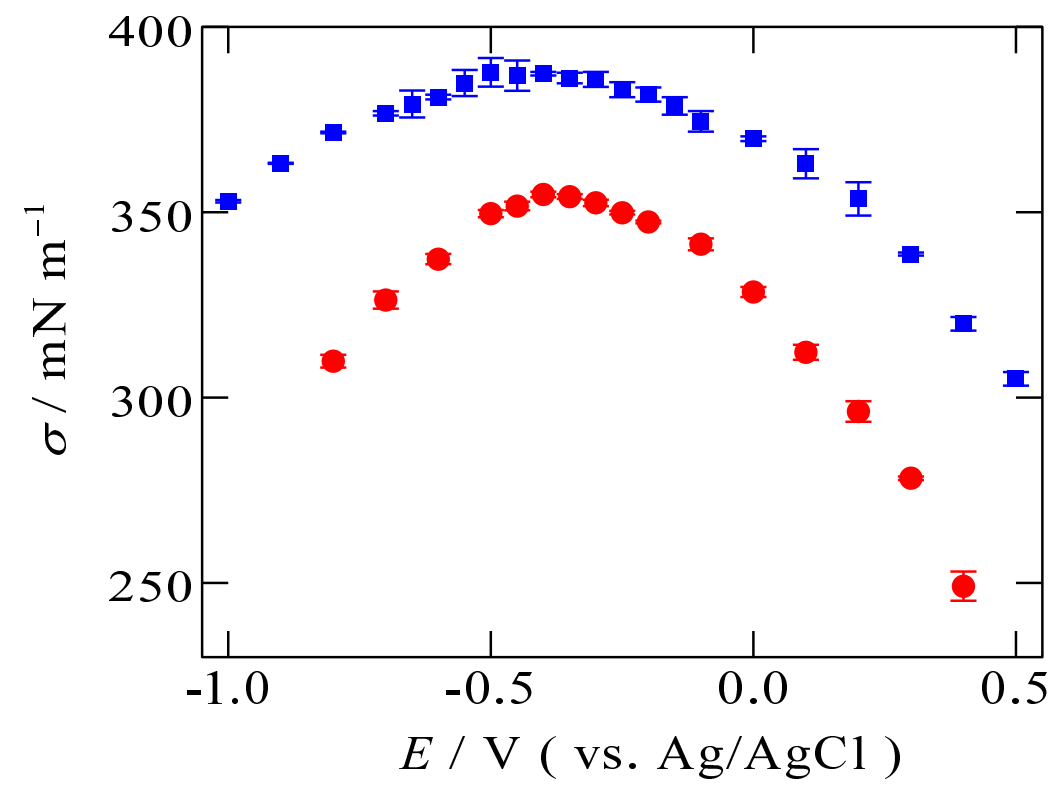

Fig.1 (Nishi et al.) 


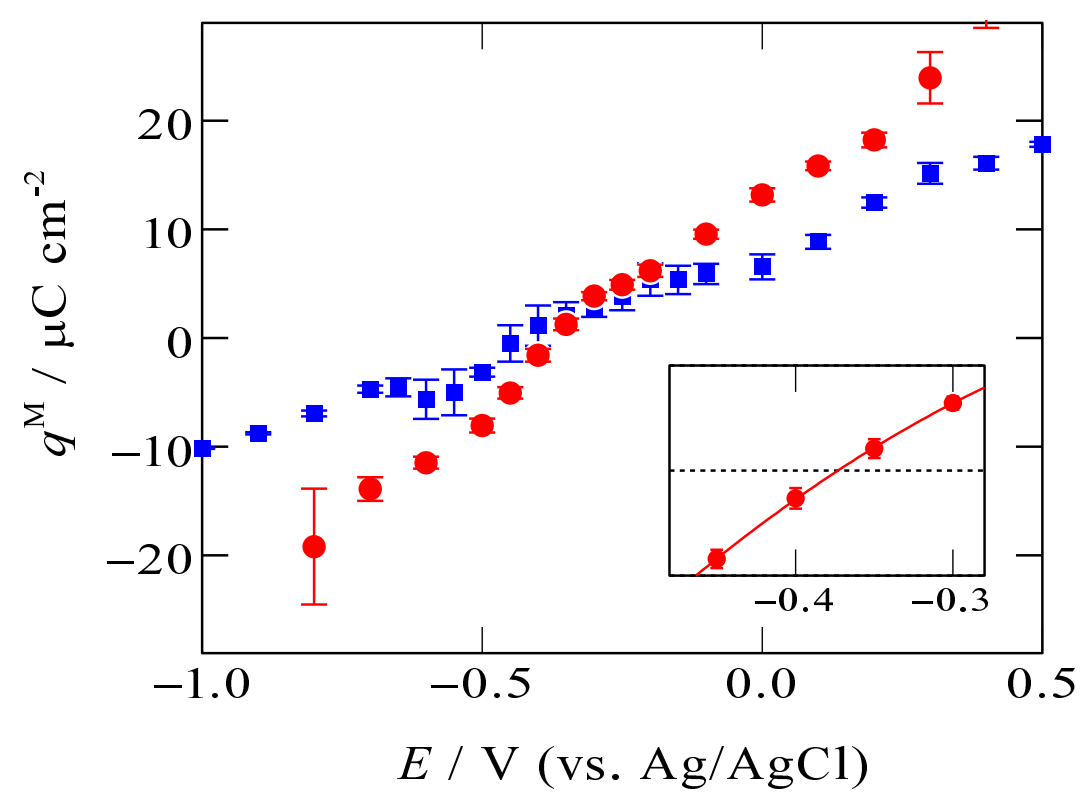

Fig.2 (Nishi et al.) 


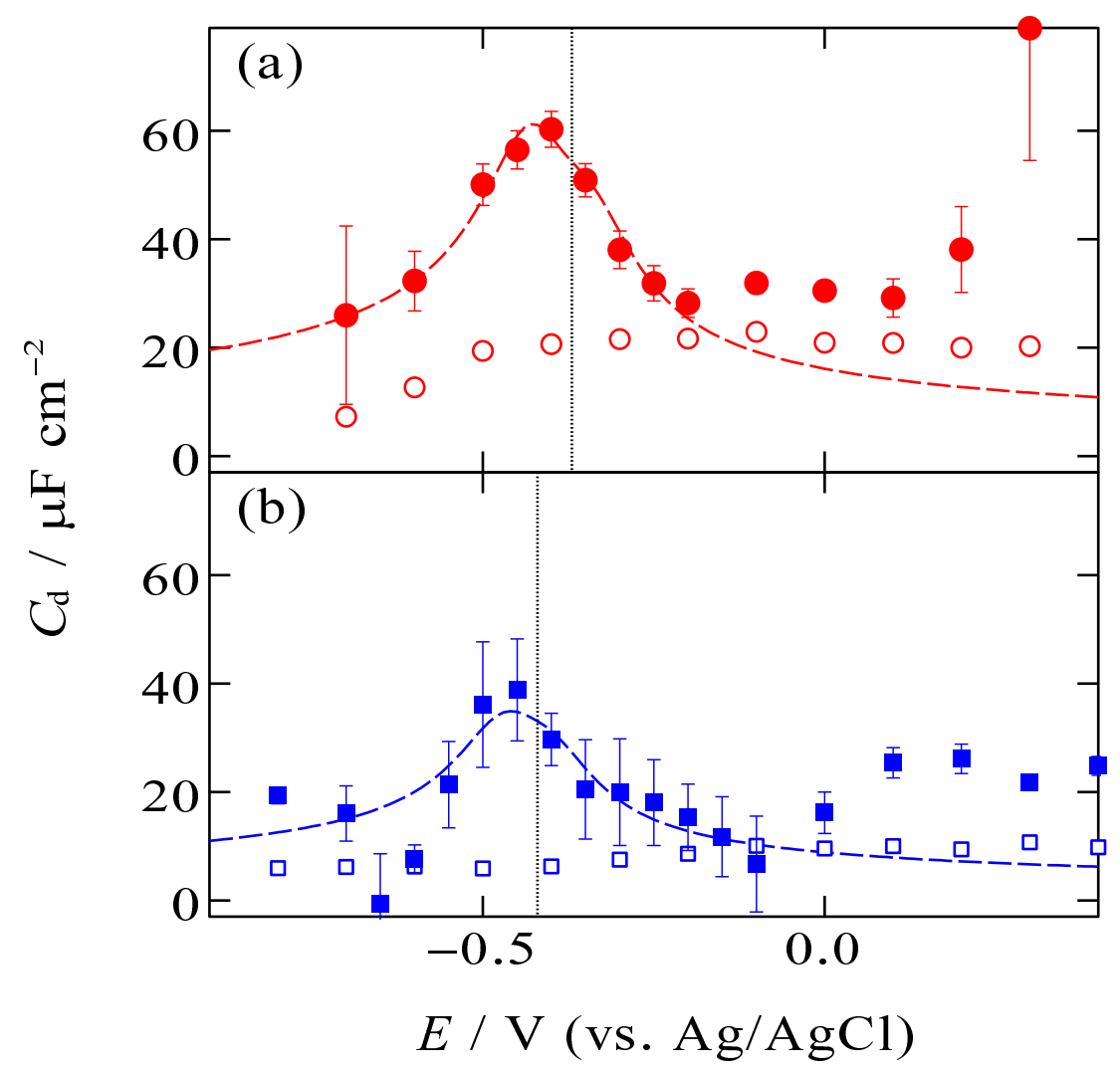

Fig.3 (Nishi et al.) 